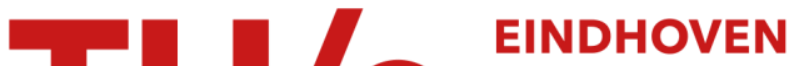 UNIVERSITY OF TECHNOLOGY
}

\section{Model-based eco-driving and integrated powertrain control for (hybrid) electric vehicles}

\section{Citation for published version (APA):}

Ivens, T., Spronkmans, S., Rosca, B., \& Wilkins, S. (2013). Model-based eco-driving and integrated powertrain control for (hybrid) electric vehicles. World Electric Vehicle Journal, 6(2), 336-344.

\section{Document status and date:}

Published: 01/01/2013

\section{Document Version:}

Publisher's PDF, also known as Version of Record (includes final page, issue and volume numbers)

\section{Please check the document version of this publication:}

- A submitted manuscript is the version of the article upon submission and before peer-review. There can be important differences between the submitted version and the official published version of record. People interested in the research are advised to contact the author for the final version of the publication, or visit the $\mathrm{DOI}$ to the publisher's website.

- The final author version and the galley proof are versions of the publication after peer review.

- The final published version features the final layout of the paper including the volume, issue and page numbers.

Link to publication

\section{General rights}

Copyright and moral rights for the publications made accessible in the public portal are retained by the authors and/or other copyright owners and it is a condition of accessing publications that users recognise and abide by the legal requirements associated with these rights.

- Users may download and print one copy of any publication from the public portal for the purpose of private study or research.

- You may not further distribute the material or use it for any profit-making activity or commercial gain

- You may freely distribute the URL identifying the publication in the public portal.

If the publication is distributed under the terms of Article 25fa of the Dutch Copyright Act, indicated by the "Taverne" license above, please follow below link for the End User Agreement:

www.tue.nl/taverne

Take down policy

If you believe that this document breaches copyright please contact us at:

openaccess@tue.nl

providing details and we will investigate your claim. 


\title{
Model-Based Eco-Driving and Integrated Powertrain Control for (Hybrid) Electric Vehicles
}

\author{
Ivens, T. ${ }^{1}$, Spronkmans, S. ${ }^{2}$, Rosca, B. ${ }^{2}$, Wilkins, S. $^{2}$ \\ ${ }^{1}$ TNO Science and Industry - Automotive, P.O. Box 756,5700 AT Helmond, The Netherlands, thomas.ivens@TNO.nl \\ ${ }^{2}$ TNO Science and Industry - Automotive, P.O. Box 756,5700 AT Helmond, The Netherlands
}

\begin{abstract}
The Netherlands Organisation for Applied Scientific Research (TNO) is engaged in research, development and testing of a range of technologies relating to hybrid and electric vehicle energy management and performance. The impact of driver behaviour on vehicle energy consumption is a significant factor, and one which can often be reduced with eco-driving, typically 5-10\% or higher in some cases. Eco-driving can be extended not only to take into account information sources, improved user acceptance, and integration with powertrain control. In this paper, TNO illustrates the possible applications of model-based control for (hybrid) electric vehicles and shows preliminary results of the developed system.
\end{abstract}

Keywords: HEV (hybrid electric vehicle), energy consumption, vehicle performance, eco-driving

\section{Introduction}

Over the past decades, there has been an increased rise on the number of hybrid and electric vehicles, which is a trend expected to continue in order to meet the European greenhouse gas emission levels. One of the main market points of HEVs and EVs is their improved fuel economy and effective range respectively. It is therefore unsurprising that many of the vehicles on the market are closely linked with driver feedback systems, wherein the successful operation of the vehicle is centred around a strong driver-vehicle combination. As increasing degrees of integration of ICT services and coupling of PHEV and EVs with the grid become more prevalent in future, the comprehensive management of energy becomes a key topic.

Besides energy efficiency, energy storage is important for electric vehicles specifically. Lithium-ion batteries have emerged as a preferred means of energy storage, partly owing to their high energy density.

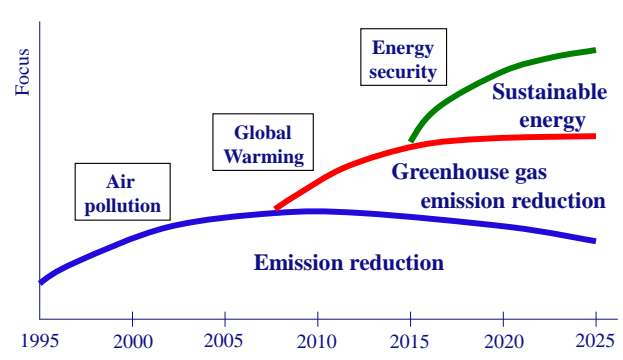

Figure 1: Trends and predicted focus in powertrain development [8]

However, it is recognised that the current cost and energy density (both mass and volume) for battery systems are major limiting factors in the mass take-up of EVs, particularly with public concern over widespread anxiety that limited driving range is predominant over conventionally fuelled alternatives.

Furthermore limitations of existing battery energy storage (and the requirement to keep battery pack size to a minimum) prompts more efficient and effective use of the available energy. The combination of measures to ensure better energy 
efficiency is a significant topic, and comprises many contributing factors.

To mitigate range anxiety, it is important to both offer an accurate range prediction to the driver, as well as a comprehensive means to manage the energy efficiency within the vehicle and improve wherever possible.

\section{Eco-Driving}

The area of eco-driving, particularly that supported by human-machine interfaces (HMI) has received increased interest over recent years, for both conventional and advanced powertrains. The features of eco-driving typically include, but at not limited, to the following [1]:

- Moderation of acceleration

- Keeping the engine at low RPM: moderation of gear shifts

- Anticipating traffic signals avoiding sudden start-stops

- Maintaining an even driving pace (including use of cruise control and coasting)

- Driving at or below the speed limit

- Eliminating excessive idling

- Minimising use of auxiliary systems

Eco-driving for both conventional light duty and heavy duty range from $5-10 \%$ in fuel consumption reduction dependent partially on whether an HMI is provided, as well as the time and mode of vehicle operation [1]:

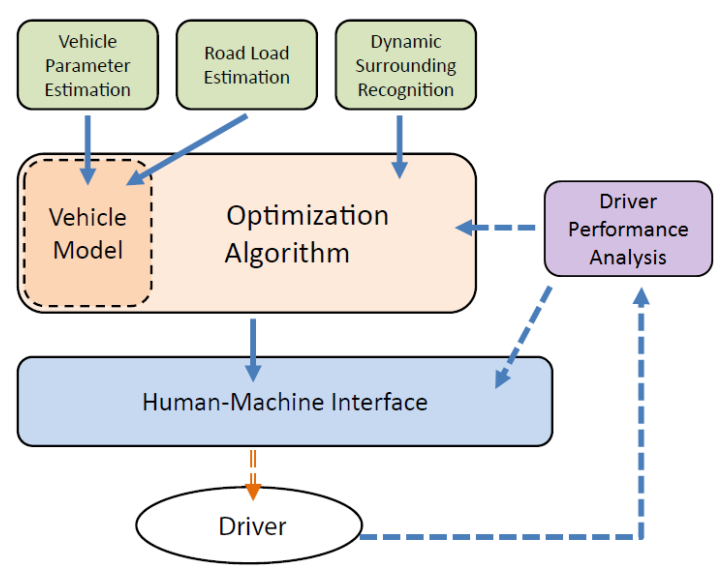

Figure 2: Schematic of Eco-Driver Architecture [6]

For the purposes of this paper, we categorise ecodriving support into five levels:
- Level 1: General eco-driving training and the offline provision of advice

- Level 2: Data collection from OBD or CAN to provide driver advice offline

- Level 3: Integrated (in-vehicle) coaching system making use of a predictive model

- Level 4: Integrated advice system taking input from external information sources

- Level 5: Fully integrated system: including external sources and interaction with powertrain control

Level 1 does have an immediate effect on energy consumption, but the effect of a training is gradually lost over time [2][17].

The next generation of systems under development (Levels 4-5) take additional information sources relating to traffic light state, and other vehicle and external information to present a more comprehensive view. This is further described in Section 3. Because of this effect, driver support systems are a logical next step. The system complexity increases with the eco-driving support level. Because of driver acceptance, it is important to provide accurate advice to the driver. A modelbased approach therefore is very useful [7].

Within the market for hybrid and electric vehicles, many of the existing commercially used vehicles have some form of driver fuel-efficiency feedback (typically Level 1-3). Some of these approaches extend to mode switching (e.g. the Honda Eco Assist and ECON mode, NISSAN CARWINGS and Toyota Prius Eco Mode). More advanced systems of level 3 and higher typically have an architecture that is similar to the one shown in Figure 2: information is gathered from the vehicle and its environment. Predictions make use of a vehicle model and are used for generating advice. Advice (consisting of feedback and/or feedforward) is presented to the driver in an HMI and can be altered based on the driver's performance.

One important trade-off one encounters when it comes to eco-driving is between energy consumption and time. Lower vehicle speeds (usually) lead to lower energy consumption. However, a driver's decisions are based on time . For (plug-in H)EV's, the charging time has to be taken into account as well. Model-based routing advice can also take into account charging times and charge station availability[12]. 


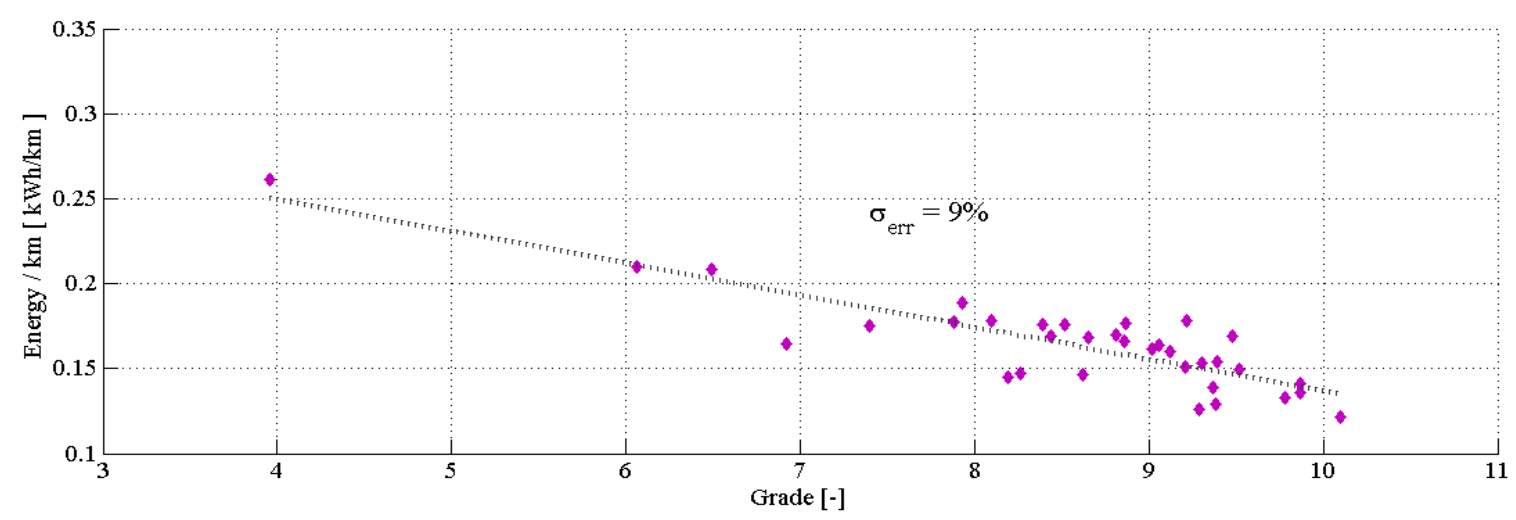

Figure 3: Energy Consumption as a Function of Driver-Cycle Grade [15]

\section{Integrated Eco-Driving}

Eco-driving is achieved if the vehicle speed is such that the energy efficiency for travelling a specific distance is improved. Advising the driver to control the vehicle speed to the desired speed can be achieved in various ways. Potential savings increase from Levels 1 to 4 simply because the driver behaviour can be advised better if more data on the actual situation are available. The Sentience programme demonstrated an integrated EMS (Energy Management System), saving through simulation of $6-16 \%$ with track demonstration at 5-24\% using a hybrid [18]. Zhang showed in simulation a saving of $13 \%$ for a PHEV [20] although it is most likely to be this effective in hilly environments [9].

External information can be used to identify future constraints on the vehicle's path. Then, using a vehicle model, a vehicle-specific advice can be generated to guide the driver through constraints set by his environment. An illustrative example is provided in Figure 4, which origins from a previous project [10] on using an electronic horizon (eHorizon). A realworld scenario was recorded and used as a baseline. The hybrid truck (orange, at bottom of figure) receives information on the (future) traffic light states: distance to the intersection, time-to-red, time-to-green and length of the queue. Subsequently, the driver is advised to adapt the vehicle speed to that. The green dashed area indicates a queue at the intersection, where it is assumed that the queue dissolves linearly.
The eco-friendly alternative speed profile is driven on a closed test track as it would not be possible to encounter the exact same situation again on the public road. Driver compliance was perfect, as he was accurately instructed by the passenger. The fuel savings resulting from this traffic light preview information is significant: 14 per cent, which corresponded to simulation results.

Although traffic light preview is not common yet, more and more test sites across Europe show that this is a trend for the future. However, integrated eco-driving in general has found its way to the market already. Most examples can be found in the heavy-duty and luxury segment [3].

Amongst others, Scania and Freightliner both have "predictive cruise controls", which take into account hill preview information and automatically adapt the cruise control set point in order to reduce the amount of braking whilst going downhill. To compensate for time loss at these slower sections, the cruise control speeds up before going uphill.

Amongst others, Porsche and BMW show "active cruise controls", which are able to adapt the vehicle speed based on radar information, but also on curve radius preview. With systems like these, both safety and energy efficiency is increased [13].

Aforementioned examples indicate that integrated eco-driving is increasingly applied. Future developments will show more automated interventions in the vehicle behavior, going towards autonomous driving. 


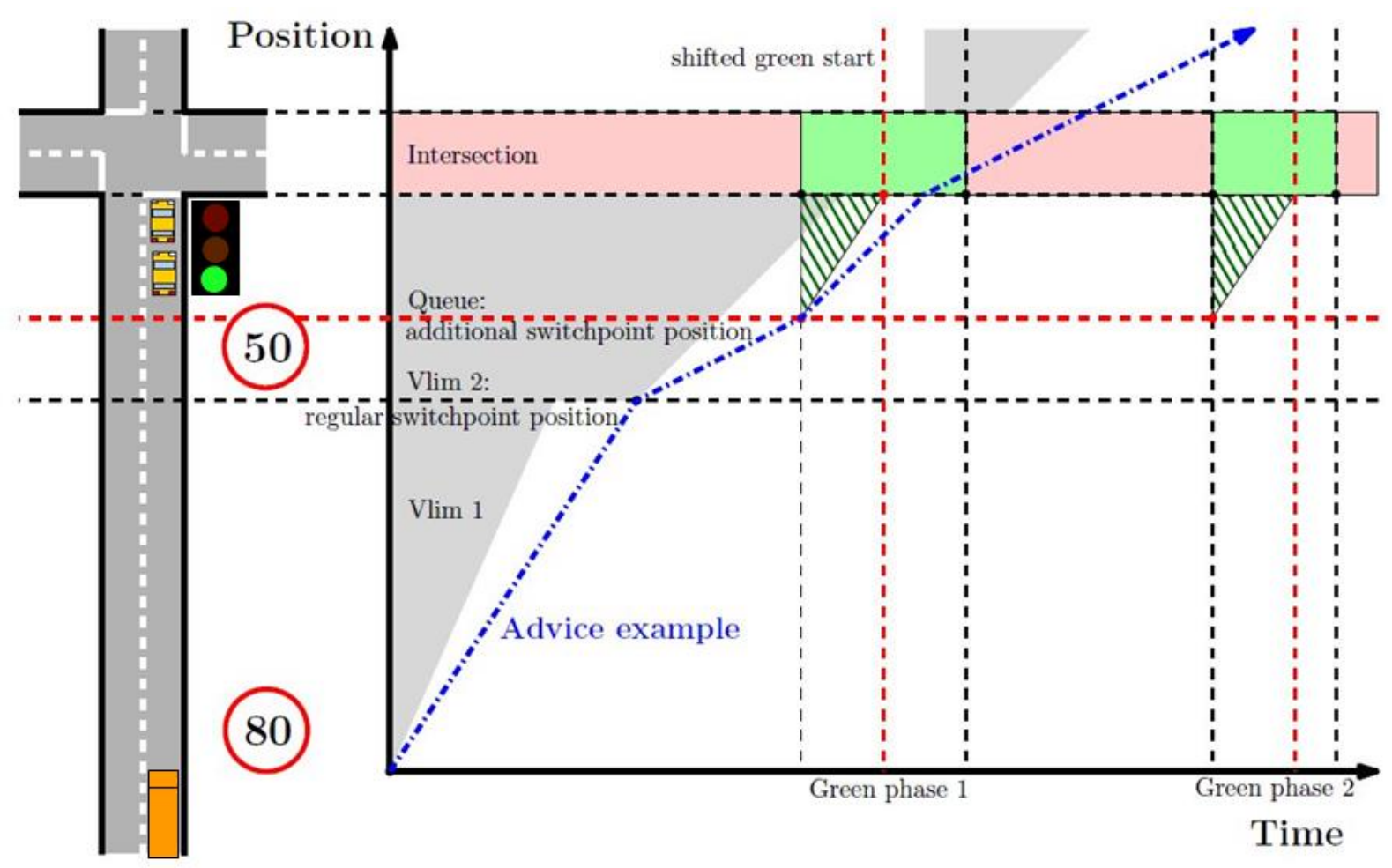

Figure 4: Illustration of eHorizon concepts for vehicle control and driver advice [10]

Advanced traffic management and a growing market share for smartphones both contribute to the availability of information for integrated systems. Together with the availability of safety systems on newer vehicles (e.g. radar and/or camera, rain sensors, etc.) the automotive world seems to be ready for advanced eco-driving.

\section{Integrated Powertrain Control}

Overall, Integrated Powertrain Control (IPC) represents a trade-off between fuel consumption, emissions, as well as maintaining driveability of the vehicle within operational cases.

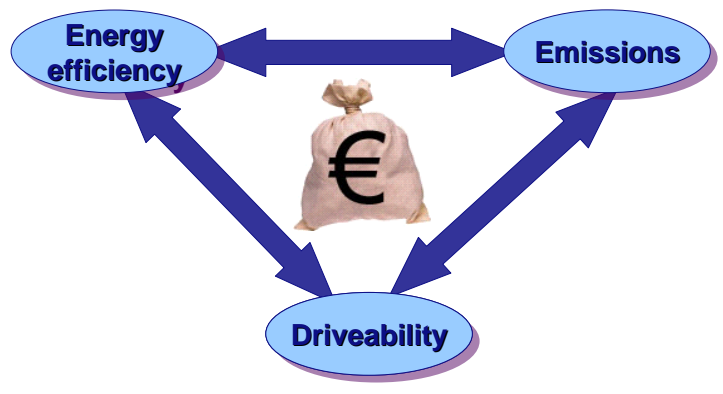

Figure 5: Integrated factors, adapted from [5]
The term 'driveability' is often subjective and requires clarification based on the context. For the purposes of this paper, the term is used to define the acceptance range for influencing the driver behaviour, without a compromise on the vehicle operation.

Control of advanced powertrains to achieve maximum energy efficiency within the applicable emission constraints has become a great challenge for the automotive industry. For maximum performance all components in the powertrain should cooperate seamlessly. IPC is a supervisory control system for powertrains of conventional, hybrid and electric vehicles that exploits system interactions in a systematic and modular way. IPC uses a cost-based optimisation strategy (typically based around ECMS) that explicitly deals with requirements on pollutant emissions and driveability [11][19].

For a number of years TNO has been developing IPC, focused on an integral approach to fuel economy, emissions and other factors/constraints. Even for long-haul applications, results have shown potential savings on running costs up to $3.5 \%$ above existing hybrid control strategies, or 
savings on pollutant emissions up to $24.9 \%$ depending on the calibration of IPC [11]. The IPC approach is extended further by accommodating external factors and monitoring of the driver behaviour, such that in the case that the driver cannot be influenced by driver coaching systems, the supervisory control system is adapted around the particular driver behaviour. Typically, a hybrid vehicle has more powertrainbased control parameters than conventional and electric vehicles, which can offer a larger degree of freedom to influences on energy efficiency for hybrid vehicles. It is therefore expected that for hybrid vehicles the potential for cost reduction via powertrain control is highest. For conventional and electric vehicles, the number of parameters to control is often less than that of a hybrid vehicle, particularly in regard to propulsion management, and therefore the impact of the driver is more significant. However, in all cases, it is recognised that the behaviour of the driver is an integral consideration for all vehicle types.

\section{Driver Classification and Impact}

It is recognised that driver behaviour plays a significant factor in the energy efficiency of vehicle [14][17]. In the case of plug-in hybrids and electric vehicles, this behaviour can extend to the charging strategies as well, recognizing the higher energy efficiency of slow charging compared to fast charging.

Rosca and Wilkins [15] present a sensitivity analysis to assess at the impact of driver behaviour on the energy consumption of a current commercial electric vehicle (Nissan Leaf). An algorithm has been developed to assign a driver-cycle grade based on a reduced-order vehicle model and driven speed profiles. In parallel, the energy consumption of the vehicle was measured at the battery.

Figure 3 shows the correlation found between the driver grade obtained by a drive cycle and the energy consumption per kilometre measured at the battery terminals of the Nissan Leaf. It can be seen that the driver-cycle grade, and as such the driver behaviour, has a significant influence on the energy consumption of the vehicle, variations of up to $50 \%$ being visible in the results. The maximum range also proves to be highly sensitive to the level of aggressiveness on the drive cycle.

The method applied to describe this effect uses two drive cycle parameters. The first is the Relative Positive Acceleration (RPA), which relates to the inertial forces that have to be overcome. The second is the Relative Cubic Speed (RCS), which is related to the drag force.

In addition to the convenience of a longer range through eco-driving, it is likely that the vehicle's battery pack will suffer from less wear. As ecodriving decreases the energy use, the depth-ofdischarge (DoD) is lower. Repeated high DoD's cause damage to the battery pack.

\section{Test Results from Driver HMI and Acceptance}

The hybrid truck example from section 3 had a "perfect driver", which followed the advice closely. However, real-world applications will require an HMI that is intuitive and therefore has a low workload. Furthermore, it is important to guide a driver within his own limits of comfort: a driver should still feel safe and in control of pursuing his own goals [16].

Work on testing realistic HMI's has been developed over several projects, and most recently in EcoDriver [3] which runs from October 2011 September 2015. This section illustrates both simulation and real world tests of the integrated eco-driver system.

As shown in section 3, driver behaviour plays a significant role in the energy efficiency of the vehicle. Convincing the driver to adapt his behaviour to the advice is necessary for the advice to have impact. By giving the correct advice the difference between actual driving behaviour and optimal behaviour can be reduced. Higher compliance, i.e. how much the driver follows the advice, means more impact. High compliance means that the driver is willing to follow the advice. Whether or not the driver accepts the advice depends on several factors, such as credibility of the advice, possibility to actually follow the advice and the manner in which the advice is presented to the driver. This last part, the human machine interface (HMI) has been tested and developed in several projects, most recently in EcoDriver [4]. This section illustrates both 
simulation and real world tests of the integration of an eco-driver system.

In the ecoDriver project, besides the practical implementation of a an ecodriving HMI, several fundamental principles of ecodriving HMI's have been tested. A selection of the most interesting principles and results found will be described in this section.

\section{Personalization}

One of the findings of social psychology that are relevant for increasing acceptance of HMI's is related to personalization. The idea behind this concept is that different people respond differently to different advice or feedback. In other words, choosing the appropriate form of the advice or feedback increases acceptance. In a series of tests, different groups of drivers that were identified to be sensitive to different kinds of feedback were exposed to HMI's tailored to those different group. The effects of personalization were studied and two dimensions were identified. Their value orientation was plotted on one dimension. This indicated whether the driver belonged to a group sensitive to increase their eco-driving performance for their own personal gains and or for the better of all.

Another dimension to split types of advice or feedback on is the goal orientation of drivers, i.e. whether drivers are more interested in developing their own skills or in comparing their current performance with other people. An experiment comparing the effects of personalization on this goal orientation dimension, performed in the ecoDriver project, showed the effects of tailoring the HMI to the type. In the experiment the behavior of drivers with a performance goal orientation was compared with the behavior of drivers with a learning goal orientation. Both groups drove with a basic advice HMI, indicating solely the most energy efficient speed to drive at and two HMI's that were tailored to the groups. One was tailored to the learning orientation group, the other to the learning orientation group.

First results show that the performance group gave the (mismatched) learning oriented HMI a lower rating on acceptance, ease of use, favoritism and a lower general rating. The learning oriented group rated both adapted systems higher than performance group and rated the systems also higher than the basic HMI on acceptation, general rating and favored both adapted systems over the basic version.

Overall compliance was better with the adapted HMI's; here no clear difference between groups was found. Compliance with advised speed around traffic lights, showed a group difference, where both the learning and performance oriented complied best when using their matched HMI.

Both subjective and objective data suggest that personalizing the HMI increased the impact of the given advice by increasing acceptance or compliance.

\section{Driver type detection}

From the previous subsection one can draw the conclusion that it is important to know what kind of driver is behind the wheel. This may help in personalizing the advice and increasing the impact of the advice because of better compliance. As described in section 3, there are also different driver behavior aspects that have a direct impact on energy efficiency. Taking these characteristics into account, i.e. giving the correct advise for this particular driver, may increase the impact of the advice too. For the latter, we also need to know what kind of driver is in the vehicle. The preferred method for this would be that a system within the vehicle can establish the type of driver from driving behavior recorded and analyzed while driving. An automatic system would mean low intrusiveness which is necessary for such a system to be acceptable for drivers. Driver type detection would preferably be based on driving behavior measured via OBD or CAN and include driving speed, acceleration, rpm and other measures that may be associated with a particular driver type.

Within the ecoDriver project a prototype has been developed for on-trip driver type detection. The prototype makes use of a two-stage approach adopting Neural-Symbolic Cognitive Agents to model the performance and driver type indicators. It also enables the extraction of learned knowledge in human readable form for offline validation of the models. To develop a method for on-trip automated driver type detection we need to model the correlations between the collected vehicle data and driver type indicators. Driver types, such as described in the previous section on personalisation, need to be correlated to performance indicators that describe low level driving behaviour. These performance indicators are based on temporal relations in the collected 
vehicle data (e.g. "RPM $>4000$ for a large amount of time").

Evaluation results on the training data and data left out of the training set are very good (average F1-score (test accuracy between 0 and 1) and average MCC (Matthews Correlation Coefficient between -1 and +1 ) were determined to be 0.528 and 0.727 respectively, with the exception of a few participants for which the prediction on the social and sportive were incorrect. Reasons for these exceptions can be that the used models need further optimization and/or that the driver type indications from the questionnaire contradicted with the actual driving behaviour. To deal with the latter the system could take into account future pre-trip questionnaires with regular interval (e.g. every month or half a year) to update the models with new information on driver type indications and related driving behaviour.

The overall conclusion is that the driver type detection module works fine, perhaps even better than may be expected from results reported in literature.

\section{Discussion and Conclusion}

It is possible to collect data from a vehicle and provide eco-driving advice, making use of OBD, CAN or a nomadic device. The advice is then based on this data and checks the conformity with the advice methodology described in Level 1. When an eco-coaching system can make use of a vehicle model, advice can really be generated for a specific vehicle. This way efficient operating points and many vehiclespecific control strategies (e.g. the gear-shifting algorithm in an automatic transmission) can be taken into account.

When data is collected from the vehicle, the driver behaviour can be compared with alternative behaviour and using the vehicle model, the driver can receive quantitative feedback. If the driver type is known, the feedback can also be personalized. Some drivers might be triggered if they beat their own personal record, whereas others are more competitive and can better be motivated through a comparison with others. This way of personalization is likely to increase the acceptance level even more.
When an eco-coaching system can make use of external data, an advice for the future becomes possible. Often, this is called eHorizon-based advice. One can use data from the infrastructure, but also from a radar/LIDAR system to monitor other road users.

The combination of an advanced powertrain and a well-performing driver seems to be a good one. Because of the complexity, integrated systems guide the driver in performing eco-friendly and are more and more intervening in addition to that. It can be expected that future ecodriving systems have higher intervention levels and therefore the vehicles will become more autonomous as well.

\section{Acknowledgments}

This study has benefitted from funding from ENIAC SE2A, EcoDriver. 


\section{References}

[1] Barkenbus, J. Eco-driving: An overlooked climate change initiative, Energy Policy 38 (2010) 762769, 2009

[2] B. Degraeuwe and B. Beusen: Corrigendum on the paper "On-board data logging devices to study longer-term impact of an eco-driving course, Transportation Research Part D 19 (2013) 48-49.

[3] EcoDriver Consortium, D11.1: A state of the art review and user's expectations. ecoDriver Project. Retrieved from www.ecodriverproject.eu.

[4] EcoDriver Project Website http://www.ecodriverproject.eu/

[5] Foster, D., Cloudt, R., Willems, F. Towards Integrated Powertrain Control: Exploiting Synergy between a Diesel Hybrid System and Aftertreatment System in a Distribution Truck, IEEE Intelligent Vehicles Symposium, Eindhoven University of Technology, 2008

[6] Ivens, T.W.T., Driver Behavior Optimization Using Preview Information, Eindhoven University of Technology, CST 2011.53, August 2011

[7] Kamal, M.A.S. et al. On Board Eco-Driving System for Varying Road-Traffic Environments Using MPC - IEEE Technical Paper 978-1-42445363-4/10 pp. 1636-1641.

[8] Kessels, J. Advances in Integrated Powertrain Control, Presented at Automotive Summit 2010 (Brussels). Retreived from www.via3.at

[9] van Keulen, T.A.C., et al. Energy Management in Hybrid Vehicles: Benefit of Prediction, Eindhoven University of Technology, TNO Automotive - Proceedings of the $8^{\text {th }}$ International Symposium \& Transport Expo Innovative Fahrzeug-Getriebe (2009) pp. 1-11

[10] Koornneef, G., van Goethem, S., eHorizon for hybrid vehicle controls and driver advice, http://www.eniac-se2a.com , 2009

[11] J.T.B.A. Kessels et. Al., Integrated Energy \& Emission Management for Hybrid Electric Truck with SCR aftertreatment, Proceedings of the FISITA World Automotive Congress (FISITA 2010), 30 May - 4 June 2010, Budapest, Hungary, FISITA.

[12] Malandrino et al. A Game-Theoretic Approach to EV Driver Assistance Through ITS, Politecnico di Torino - IEEE Technical Paper 978-1-46732569-1/12 pp. 2541-2546

[13] P. Markschläger et al. Assistance System for Higher Fuel Efficiency, ATZ worldwide November 2012, Volume 114, Issue 11, pp. 8-13.
[14] J. Nader: Measurement of the impact of driving technique on fuel consumption: preliminary results, Roads \& Transportation, Technical Note TN-172, 1-6

[15] B. Rosca and S. Wilkins: On the Sensitivity of the State of Batteries on Driver Behaviour within the EV Powertrain, EEVC, Brussels, Belgium, November 19-22, 2012

[16] H. Summala: Towards Understanding Motivational and Emotional Factors in Driver Behaviour: Comfort through Satisficing, Modelling Driver Behaviour in Automotive Environments (2007), 189-207

[17] A.E. af Wahlberg : Long term effects of training in economical driving: Fuel consumption, accidents, driver acceleration behaviour and technical feedback, International Journal of Industrial Ergonomics 37 (2007), 333-343

[18] Walker, R. L., Sentience - Using Electronic Horizon Data to Improve Vehicle Fuel Economy, UK's Transport Research Laboratory (TRL) RTIC 2008 Conference, pp 1-6

[19] F. Willems et. Al., Integrated Powertrain Control to Meet Low CO2 Emissions for a Hybrid Distribution Truck with SCR-DeNOx System, Proceedings of ASME 2011 Dynamic Systems \& Control Conference, 31 October - 2 November 2011, Arlington, Virginia, (pp. 1-6). ASME.

[20] Zhang, C., Vahidi, A., Real-Time Optimal Control of Plug-in Hybrid Vehicles with Trip Preview, Clemson University - IEEE Technical Paper 978-1$4244-1 / 10$ 


\section{Authors}

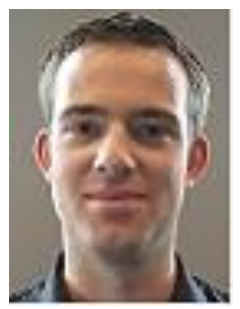

Thomas Ivens obtained his M.Sc. degree in Mechanical Engineering from the Eindhoven University of Technology, in 2011. He is currently a research scientist at TNO, the Dutch Organization of Applied Research, in the Powertrain Department. His activities include powertrain modelling and control and developing ecocoaching algorithms. $\mathrm{He}$ is currently involved in the EcoDriver European project, developing algorithms that provide driver coaching in various situations.

Stefan Spronkmans obtained his M.Sc. degree in Electrical Engineering from the Eindhoven University of Technology, in 2010. He is currently a research scientist at TNO, the Dutch Organization of Applied Research, in

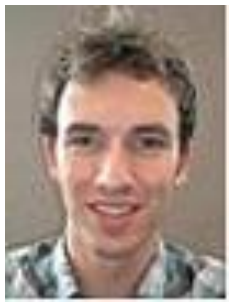
the Powertrain Department. His activities include powertrain modelling and control and developing ecocoaching algorithms. $\mathrm{He}$ is currently involved in the EcoDriver European project, developing algorithms that provide driver coaching in various situations.

Bogdan Rosca obtained his M.Sc. degree in Automotive Technology from the Eindhoven Technical University, in 2011. He is currently a research engineer at TNO, the Dutch Organization of Applied Research, in the Powertrains Department. His activities include battery modelling and state estimation, powertrain modelling and control and driver behaviour characterization. $\mathrm{He}$ is currently involved in the ABattReLife European project, studying the aging behaviour of Li-ion batteries in

automotive applications.

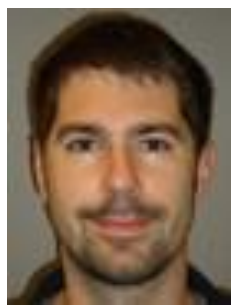

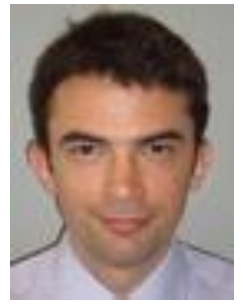

Steven Wilkins has a background in hybrid and electric powertrain modelling and simulation, originally based at Imperial College London where he completed his doctorate and post-doctoral studies, and retains a position as a visiting academic. $\mathrm{He}$ is now based in the Netherlands as a research scientist within $\mathrm{TNO}$, the Dutch Organization of Applied Research. He is a member of the Powertrains department, is an active member of EARPA, and is involved in the ABattReLife European project amongst others. 